\title{
Asymmetric Dimethylarginine (Adma): A Novel Marker of Endothelial Dysfunction in Hyperthyroidism
}

\author{
Al-Nuzaily MAK ${ }^{2 *}$, Tash FM², Farid $\mathrm{MT}^{2}$, Al- \\ Habori $\mathrm{MA}^{3}$, Boshnak $\mathrm{H}^{4}$ and Abdelaal $\mathrm{H}^{5}$ \\ ${ }^{1}$ Department of Haematology, Sana'a University, Yemen \\ ${ }^{2}$ Department of Medical Biochemistry, Ain Shams \\ University, Egypt \\ ${ }^{3}$ Department of Medical Biochemistry, Sana’a University, \\ Yemen \\ ${ }^{4}$ Department of General Surgery, Ain Shams University, \\ Egypt \\ ${ }^{5}$ Department of Clinical Pathology, Ain Shams University, \\ Egypt
}

*Corresponding author: Al-Nuzaily MAK, Department of Haematology, Sana'a University, Yemen

Received: J anuary 04, 2017; Accepted: March 27, 2017; Published: April 04, 2017

\begin{abstract}
Disturbance of thyroid function, mainly hyperthyroidism has long been associated with cardiovascular complications. Clinical studies suggested that dysfunction of endothelial L-arginine-nitric oxide pathway is related in the development of Endothelial Dysfunction (ED) and to further vascular events. Asymmetric Dimethylarginine (ADMA), an endogenous competitive inhibitor of Nitric Oxide (NO) synthase, inhibits NO production by competing with L-arginine and its concentration was strongly predictive of premature cardiovascular disease. Symmetric Dimethylarginine (SDMA), another endogenous arginine analogue, is unable to inhibit NO synthase. The aim of this study was to examine the plasma levels of ADMA, SDMA, L-arginine and NO metabolites in hyperthyroid females and healthy volunteers. In this study sixty females (40 patients with primary hyperthyroidism and 20 normal healthy control) were included and subjected to determination of levels of serum fT3, fT4 and TSH by ELISA technique, plasma ADMA, SDMA and arginine by HPLC method, whereas serum NO metabolites levels were measured by colorimetric method. Our results showed that there were a significant increased ADMA and arginine levels and decreased NO metabolites levels in hyperthyroid patients than control subjects. In conclusion, ADMA was elevated in hyperthyroid patients. Elevation of ADMA was associated with decreased NO production, which could be related to endothelial dysfunction and its cardiovascular alterations. ADMA may be a novel risk factor for endothelial dysfunction in hyperthyroidism. Further studies should be doing to measure and assess the endothelial function itself in these patients.
\end{abstract}

Keywords: Hyperthyroidism; Cardiovascular Disease (CVD); Endothelial Dysfunction (ED); ADMA; SDMA; Arginine; NO; Thyroxine; Triiodothyronine; Thyrotropin

\section{Introduction}

Disturbance of thyroid function, mainly hyperthyroidism has long been associated with Cardiovascular (CV) manifestations such as tachycardia, systolic hypertension, heart failure and increased probability of cardiovascular mortality [1].

The endothelium plays a crucial role in the maintenance of vascular tone and structure. One of the major endothelium derived vasoactive mediators is Nitric Oxide (NO), which is formed from the amino acid precursor L-arginine by Nitric Oxide Synthase (NOS). NO produced by the vascular endothelium is involved in a wide variety of regulatory mechanisms of the cardiovascular [2]. NO is the major mediator of endothelium dependent vasodilation and mediates many of the protective functions of the endothelium and therefore is considered as essential anti-atherosclerotic factor [3]. NO inhibits oxidative modification of plasma lipoproteins and superoxide radical elaboration, inhibits platelet adhesion and aggregation, inhibits monocyte adhesion to the endothelium and inhibits proliferation of vascular smooth muscle cells [4-6].

Dysfunction of the endothelial L-arginine-nitric oxide pathway is related in the development of Endothelial Dysfunction (ED) and to further vascular events. Clinical studies suggested that endothelial dysfunction together with impaired nitric oxide biosynthesis and bioavailability were the possible causes of such complications [7].

Asymmetric Dimethylarginine (ADMA) is an endogenous competitive inhibitor of NOS, as first described in 1992 by Vallance, et al. [8]. ADMA is derived from hydrolysis of proteins containing methylated arginine [9]. ADMA inhibits NO synthesis by competing with the substrate of $\mathrm{NO}$, L-arginine, leading to endothelial dysfunction and, consequently, to atherosclerosis. Moreover, ADMA has been considered as an independent risk factor for Cardiovascular Disease (CVD). There are numerous studies that show a relationship between elevated ADMA concentration and CVD [10]. Elevated ADMA concentration is highly prevalent in various disease states including end-stage chronic renal failure [11,12], diabetes mellitus [13-15], hypercholesterolemia [16], hyperhomocysteinemia [17], hypertension [18,19] and CVD [20-23]. Clearance of ADMA from the plasma occurs by renal elimination or largely through enzymatic degradation by intracellular Dimethylarginine Dimethylaminohydrolase (DDAH) [24,25].

In the present study we examined the plasma levels of ADMA, SDMA, L-arginine and NO metabolites in hyperthyroid females and healthy volunteers. 


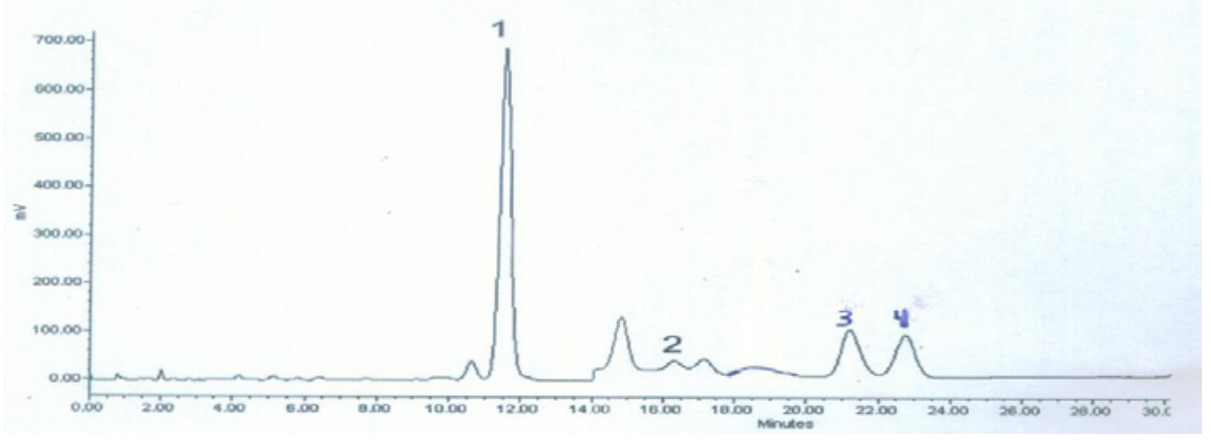

Figure 1: Chromatogram of a derivatised plasma extract containing $100 \mu \mathrm{mol} / \mathrm{L}$ Arginine, $20 \mu \mathrm{mol} / \mathrm{L}$ MMA, $10 \mu \mathrm{mol} / \mathrm{L}$ ADMA and $10 \mu \mathrm{mol} / \mathrm{L}$ SDMA. The internal standard (MMA) was used at concentration of $20 \mu \mathrm{mol} / \mathrm{L}$. Peak identification: 1 Arginine, $2 \mathrm{MMA}, 3$ ADMA, 4 SDMA. The change in sensitivity of the fluorescence detector is at $14 \mathrm{~min}$.

\section{Subjects and Methods}

\section{Subjects}

This study was conducted Ain-Shams University Hospitals from January to March 2009. The patient's group consisted of 40 hyperthyroid females (mean age $\pm \mathrm{SD}, 37.0 \pm 6.6$; median, 38.0 ; ranged from 25 to 55 years old) who were admitted to in the endocrinology and general surgery departments. These patients were recently diagnosed with primary hyperthyroidism by ELISA method and diagnosis based on elevated levels of serum FT4 and FT3 and low TSH levels. The majority of patients admitted to the above clinics were females who were pre-diagnosed by thyroid ELISA result within a week while the other few patients were males and not pre-diagnosed so we select females in this study. The control group consisted of 20 healthy females (mean age $\pm \mathrm{SD}, 30.4 \pm 5.9$; median, 29; ranged from 23 - 43 years old). All participants gave their consent to share in this study.

\section{Sample collection}

Venous blood samples $(5 \mathrm{ml})$ were withdrawn under complete aseptic condition from each of controls and patients. From this $5 \mathrm{ml}$, $3 \mathrm{ml}$ were put in heparinised tube and $2 \mathrm{ml}$ in plain tube. Heparinised samples were mixed well and separated by centrifugation within 30 minutes of collection at $4000 \mathrm{xg}$ for 5 minutes and then stored frozen at $-80^{\circ} \mathrm{C}$ for later estimation of arginine, ADMA and SDMA levels. Samples of plain tubes were left to clot for 30 minutes. Serum was separated by centrifugation at $4000 \mathrm{x}$ g for 5 minutes and stored at $-80^{\circ} \mathrm{C}$ until analysis and estimation of NO metabolites, FT3, FT4 and TSH levels.

\section{Biochemical methods}

Determination of ADMA, SDMA and Arginine: Plasma ADMA, SDMA and arginine were performed using HPLC assay described by $[14,15]$. The materials required for ADMA, SDMA and Monomethylarginine (MMA) were obtained from Sigma, whereas arginine and concentrated (25\%) ammonia from Merck. OPA (ortho-phthaldialdehyde) and 3-mercaptopropionic acid were obtained from Fluka. HPLC grade acetonitrile and methanol were from $\mathrm{BDH}$. All other chemicals were of analytical grade. Oasis MCX cation-exchange SPE columns (30mg, ml) were supplied by Waters OASIS Corporation, Ireland.
The analysis was carried out in the National Centre for Researches (NCR) in Cairo. Egypt and run on a Waters 600 Controllar Delivery System (Waters Co. MA, USA) with a fluorescence detector (Waters 474), a 20ml sample injector (Rheodyne 7725i manual injector) and LC workstation equibed with Waters Millennium 32 version 4.0 software for data collection and acquisition.

Chromatography was performed on a Symmetry C18 column ( $3.9 \times 150 \mathrm{~mm} ; 5 \mu \mathrm{m}$ particle size; $100 \AA$ pore size) with a 10x3-mm guard column packed with the same stationary phase (Waters). Mobile phase A consisted of $50 \mathrm{mM}$ acetate buffer ( $\mathrm{pH}$ 6.3), containing 9\% (methylase I activity) acetonitrile and mobile phase B was acetonitrile/water $(50 / 50, v / v)$. Separation was performed under isocratic conditions with $100 \%$ mobile phase $\mathrm{A}$ at a flow rate of $1.5 \mathrm{ml} / \mathrm{min}$ and a column temperature of $30^{\circ} \mathrm{C}$. After elution of the last analytes, strongly retained compounds were quickly eluted by a strong solvent flush. Between 22 and 23 min the gradient returned to initial conditions and the column was equilibrated for an additional $7 \mathrm{~min}$, resulting in a total run time of $30 \mathrm{~min}$. An injection volume of $20 \mu \mathrm{l}$ was used. Fluorescence was measured at excitation and emission wavelengths of 340 and $455 \mathrm{~nm}$, respectively (Figure 1).

Calibration curves were constructed by plotting the peak area ratios of analytes over internal standard (Y) versus analytes concentration (X). For the analysis of plasma samples, single-point calibration was performed with a standard containing $100 \mu \mathrm{M}$ Arginine and $10 \mu \mathrm{M}$ each of ADMA and SDMA. The Intra-assay precision of method was $<8 \%$, the correlation coefficients were $>0.99$ and the detection limit of the assay was $0.1 \mu \mathrm{M}$. The reference values (Mean $\pm \mathrm{SD}$ ) for females were $95.3 \pm 28.2 \mu \mathrm{mol} / \mathrm{L}$ for Arginine, $0.43 \pm 0.06 \mu \mathrm{mol} / \mathrm{L}$ for ADMA and $0.44 \pm 0.07 \mu \mathrm{mol} / \mathrm{L}$ for SDMA.

Determination of Nitric oxide (NO) metabolites: Serum NO metabolites (nitrites/nitrates) concentrations were measured by colorimetric method using kit supplied by DRG International Inc., USA and run on multiscan EX from Lab system, Finland. It based on the enzymatic conversion of nitrate to nitrite by nitrate reductase, followed by colorimetric detection of nitrite as a colored azo dye product of the Griess reaction that absorbs visible light at $540 \mathrm{~nm}$. The intra- and inter-assay coefficients of variation were $2.4 \%$ and $7.7 \%$, respectively. Recoveries of both nitrites and nitrates were $98 \%$.

Determination of thyroid hormones: Serum fT3, fT4 and 
Table 1: Serum and plasma levels of ADMA, SDMA, Arginine, Nitric oxide, FT3, FT4 and TSH in the two studied groups.

\begin{tabular}{|c|c|c|c|}
\hline $\begin{array}{c}\text { Groups } \\
\text { Variable }\end{array}$ & $\begin{array}{c}\text { Hyperthyroid Patients }(\mathrm{n}=40) \\
(\text { Mean } \pm \text { SD })\end{array}$ & $\begin{array}{c}\text { Control group } \\
(\mathrm{n}=20) \\
(\text { Mean } \pm \mathrm{SD})\end{array}$ & P value \\
\hline ADMA $(\mu \mathrm{mol} / \mathrm{L})$ & $0.75 \pm 0.19$ & $0.41 \pm 0.04$ & 0.001 \\
\hline SDMA $(\mu \mathrm{mol} / \mathrm{L})$ & $0.31 \pm 0.04$ & $0.29 \pm 0.04$ & 0.154 \\
\hline Arginine $(\mu \mathrm{mol} / \mathrm{L})$ & $69.27 \pm 7.9$ & $34.95 \pm 7.0$ & 0.001 \\
\hline Nitric oxide $(\mu \mathrm{mol} / \mathrm{L})$ & $20.77 \pm 15.80$ & $41.20 \pm 12.16$ & 0.001 \\
\hline FT3 $(\mathrm{pg} / \mathrm{ml})$ & $7.03 \pm 2.37$ & $2.72 \pm 0.64$ & 0.001 \\
\hline FT4 $(\mathrm{ng} / \mathrm{dL})$ & $3.34 \pm 1.27$ & $1.39 \pm 0.17$ & 0.001 \\
\hline TSH $(\mathrm{mlU} / \mathrm{l})$ & $0.294 \pm 0.14$ & $1.57 \pm 0.48$ & 0.001 \\
\hline
\end{tabular}

TSH concentrations were determined by ELISA technique reagent kits supplied by Human GmbH, Wiesbaden, Germany and run on multiscan EX from Lab system, Finland.

\section{Statistical analyses}

All statistical analyses were performed using the Statistical Package for the Social Sciences (SPSS software version 17.0 for Windows, Inc., Chicago, Illions, USA) to indicate the degree of significant between the mean values of the patient groups and the mean values of the corresponding controls. Descriptive data were given as mean \pm Standard Deviation (SD). All tests were two-tailed and $\mathrm{p}$ values less than 0.05 were considered statistically significant. Pearson correlation coefficients ( $r$ ) were calculated to quantify the relationships between ADMA and other variables.

\section{Results}

The results presented in (Table 1) shown that hyperthyroid patients revealed a significant increase of plasma ADMA and arginine levels and decreased NO metabolites levels compared with control subjects. ADMA level in hyperthyroidism was higher than control group $(0.75 \pm 0.19 \mu \mathrm{mol} / \mathrm{l}$ vs. $0.41 \pm 0.04$, respectively; $\mathrm{p}=0.001)$. Also arginine level was more than twice than control group (69.27 \pm 7.9 $\mu \mathrm{mol} / \mathrm{l}$ vs. $34.95 \pm 7.0 \mu \mathrm{mol} / \mathrm{l}$, respectively; $\mathrm{p}=0.001)$. ADMA and arginine levels were increased by $83 \%$ and $98.2 \%$, respectively, than in control subjects. Nitric Oxide (NO) metabolite level was significantly lower in hyperthyroid patients by $49.6 \%$ than in control subjects $(20.77 \pm 15.80 \mu \mathrm{mol} / \mathrm{l} v s .41 .20 \pm 12.16 \mu \mathrm{mol} / \mathrm{l}$, respectively; $\mathrm{p}=0.001)$. SDMA level was higher, but not significant, in hyperthyroid patients than in control subjects $(0.31 \pm 0.04 \mu \mathrm{mol} / \mathrm{l} v$ s. $0.29 \pm 0.04$, respectively; $\mathrm{p}=0.154)$. TSH level was significantly lower in hyperthyroid patients than in control subjects $(0.294 \pm 0.14 \mathrm{mIU} / 1$ vs. $1.57 \pm 0.48$, respectively; $\mathrm{p}=0.001$ ), whereas FT3 and FT4 levels were significantly higher $(7.03 \pm 2.37 \mathrm{pg} / \mathrm{ml}$ vs. $2.72 \pm 0.64 \mathrm{pg} / \mathrm{ml}, \mathrm{p}=0.001$ and $3.34 \pm 1.27 \mathrm{ng} / \mathrm{dl}$ vs. $1.39 \pm 0.17 \mathrm{ng} / \mathrm{dl}, \mathrm{p}=0.001$; respectively). In hyperthyroid patients, a significant positive correlation of ADMA was found with arginine $(\mathrm{r}=0.370 ; \mathrm{p}=0.019)$ and FT4 $(\mathrm{r}=0.844 ; \mathrm{p}=0.001)$ and a significant negative correlation with NO $(\mathrm{r}=-0.761 ; \mathrm{p}=0.001)$ and TSH levels $(\mathrm{r}=-0.373 ; \mathrm{p}=0.018)$ and non-significantly correlated with age, FT3 and SDMA levels (Table 2). NO levels were significantly positive correlated with TSH levels $(r=0.429, \mathrm{p}<0.01)$ and inversely correlated with ADMA and FT4 levels $(r=-0.611, \mathrm{p}<0.01)$ and non-significantly correlated with FT3, arginine and SDMA levels (data not shown).
Table 2: Correlations between plasma ADMA and other variables in primary hyperthyroid patients.

\begin{tabular}{|c|c|c|}
\hline \multirow{2}{*}{ Variable } & \multicolumn{2}{|c|}{ Hyperthyroidism $(\mathrm{n}=40)$} \\
\cline { 2 - 3 } & $\mathrm{r}$ & $\mathrm{P} \dagger$ \\
\hline Arginine & 0.370 & 0.019 \\
\hline Nitric oxide & -0.761 & 0.001 \\
\hline TSH & -0.373 & 0.018 \\
\hline FT4 & 0.844 & 0.001 \\
\hline FT3 & -0.237 & 0.140 \\
\hline SDMA & 0.029 & 0.858 \\
\hline Age (Year) & -0.069 & 0.673 \\
\hline
\end{tabular}

†Pearson correlation, correlation is significant at the 0.05 level (2-tailed)

\section{Discussion}

In the present study, we found that hyperthyroid patients with have increased plasma ADMA and arginine levels associated with decreased NO metabolites levels compared with control subjects. This observation was consistent with similar results that have been reported in hyperthyroidism by other studies [26,27]. ADMA may be a novel risk factor for endothelial dysfunction in humans. Elevation of ADMA is associated with impaired endothelium-dependent vasodilatation and reduced urinary nitrate excretion and this abnormality is reversed by administration of L-arginine [16].

Increased ADMA levels in hyperthyroid patients might be the result of three possible mechanisms; either increased in ADMA synthesis or decreased in renal elimination or decreased in enzymatic hydrolysis of ADMA. Several lines of evidence indicate that ADMA is derived from hydrolysis of proteins containing methylated arginine [9]. Once ADMA is released from degraded proteins, its elimination from the body is brought about by renal elimination or largely through enzymatic degradation by intracellular DDAH $[24,25]$. Although renal clearance was the first mechanism for the elimination of ADMA to be reported, with reports of the clinical consequences of ADMA accumulation in patients with advanced renal failure $[8,20,25]$, enzymatic degradation of ADMA by DDAH has attracted much attention recently and thus DDAH dysfunction may be a crucial unifying feature of increased cardiovascular risk. DDAH degrades ADMA to dimethylamine and L-citrulline. DDAH activity is found in almost all tissues, with high activities in kidney and liver [24]. Thyroid hormone up-regulates protein methylase I activity, leading to increased ADMA levels and finally decreased NO associated with hyperthyroidism [28].

On the other hand, NO metabolites levels were found to be significantly lower in hyperthyroid patients than in control subjects. ADMA inhibits NO production by competing with L-arginine. It could be hypothesized that hyperthyroidism is associated increased production of oxygen free radicals and increased lipid peroxidation which increases ADMA levels leading to decrease NO synthesis. In this study, the possible mechanisms for decreased NO metabolites could be explained by elevated ADMA levels or increased in scavenging of $\mathrm{NO}$ by superoxide anion or by lower expression of NO synthase.

Also in the present study, we found that L-arginine levels were significantly increased in hyperthyroid patients than in control 
subjects. We observed that hyperthyroidism was associated with proportional elevation of ADMA and L-arginine and the ratio between them probably remained quite constant. L-arginine competes with ADMA and SDMA for uptake by cells via Cationic Amino Acid Transporter (CAT) system [29]. As clearance of ADMA from the plasma compartment occurs also by uptake by the other cells via CAT (mainly by the kidney and liver), therefore the observed high levels of ADMA in the plasma may be due to decreased uptake via CAT [30].

Because this study included females of different age, the estrogen hormonal status may affects the endothelial NO production and ADMA metabolism in premenopausal and postmenopausal women. The fact that ADMA levels are lower in premenopausal women than in men of the same age and rise in the postmenopausal period indicates an effect of estrogens in ADMA metabolism in vivo [31]. It has been reported that estrogen deficiency in postmenopausal women might cause a decrement in Nitric Oxide (NO) bioavailability by increasing the level of ADMA, thus leading to abnormalities in endothelial function $[32,33]$. Oral estrogen therapy lowers ADMA concentrations in healthy postmenopausal women [34].

Also because this study was cross-sectional, the endothelial function itself was not measured in these hyperthyroid patients, the causality cannot be established; it is unclear if ADMA is indeed the risk factor in these patients. Therefore, further studies should be doing to measure the endothelial function itself in these patients.

\section{Conclusion}

In conclusion, ADMA was elevated in hyperthyroid patients. Elevation of ADMA was associated with decreased NO production, which could be related to endothelial dysfunction and its cardiovascular alterations. ADMA may be a novel risk factor for endothelial dysfunction in hyperthyroidism. Further studies should be doing to measure and assess the endothelial function itself in these patients.

\section{Acknowledgment}

The authors thank doctors, technician and health workers in AinShams University Hospitals and NCR for their help and cooperation during this study.

\section{References}

1. Toft AD, Boon NA. General cardiology: Thyroid disease and the heart. Heart. 2000; 84: 455-460.

2. Moncada S, Palmer RM, Higgs EA. Nitric oxide: physiology, pathophysiology, and pharmacology. Pharmacol Rev. 1991; 43: 109-142.

3. Zsuga J, Gesztelyi R, Torok J, Keki S, Bereczki D. Asymmetric dimethylarginine: a molecule responsible for the coexistence of insulin resistance and atherosclerosis via dual nitric oxide synthase inhibition. Med Hypotheses. 2005; 65: 1091-1098.

4. Chan JR, Boger RH, Bode-Boger SM, Tangphao O, Tsao PS, Blaschke TF, et al. Asymmetric dimethylarginine increases mononuclear cell adhesiveness in hypercholesterolemic humans. Arterioscler Thromb Vasc Biol. 2000; 20: 1040-1046.

5. Napoli C, Ignarro LJ. Nitric oxide and atherosclerosis. Nitric Oxide. 2001; 5: 88-97.

6. Behrendt D, Ganz P. Endothelial function: from vascular biology to clinical applications. Am J Cardiol. 2002; 90: 40L-48L.
7. Klein I, Ojamaa K. Thyroid hormone and the cardiovascular system. N Engl J Med. 2001; 344: 501-509.

8. Vallance $\mathrm{P}$, Leone A, Calver A, Collier J, Moncada S. Accumulation of an endogenous inhibitor of nitric oxide synthesis in chronic renal failure. Lancet. 1992; 339: 572-575.

9. Boger $\mathrm{RH}$. The emerging role of ADMA as a novel cardiovascular risk factor. Cardiovasc Res. 2003; 59: 824-833.

10. Leiper J, Nandi M, Torondel B, Murray-Rust J, Malaki M, O'Hara B, et al. Disruption of methylarginine metabolism impairs vascular homeostasis. Nature Medicine. 2007; 13: 198-203.

11. Kielstein JT, Boger RH, Bode-Boger SM, Schaffer J, Barbey M, Koch KM, et al. Asymmetric dimethylarginine plasma concentrations differ in patients with end-stage renal disease: relationship to treatment method and atherosclerotic disease. J Am Soc Nephrol. 1999; 10: 594-600.

12. Fleck C, Schweitzer F, Karge E, Busch M, Stein G. Serum concentrations of asymmetric (ADMA) and symmetric (SDMA) dimethylarginine in patients with chronic kidney diseases. Clin Chem Acta. 2003; 336: 1-12.

13. Abbasi F, Asagmi T, Cooke JP, Lamendola C, McLaughlin T, Reaven GM, et al. Plasma concentrations of asymmetric dimethylarginine are increased in patients with type 2 diabetes mellitus. Am J Cardiol. 2001; 88: 1201-1203.

14. Krzyzanowska K, Mittermayer F, Wolzt M, Schernthaner G. Asymmetric dimethylarginine predicts cardiovascular events in patients with type 2 diabetes. Diabetes Care. 2007; 30: 1834-1839.

15. Lajer M, Tarnow L, Jorsal A, Teerlink T, Parving HH, Rossing P. Plasma concentration of asymmetric dimethylarginine (ADMA) predicts cardiovascular morbidity and mortality in type 1 diabetic patients with diabetic nephropathy. Diabetes Care. 2008; 31: 747-752.

16. Boger RH, Bode-Boger SM, Szuba A, Tangphao O, Tsao PS, Chan JR, et al. ADMA: a novel risk factor for endothelial dysfunction. Its role in hypercholesterolemia. Circulation. 1998; 98: 1842-1847.

17. Sydow K, Schwedhelm E, Arakawa N, Bode-Boger SM, Tsikas D, Hornig B, et al. ADMA and oxidative stress are responsible for endothelial dysfunction in hyperhomocysteinemia. Effects of L-arginine and B vitamins. Cardiovasc Res. 2003; 57: 244-252.

18. Surdacki A, Nowicki M, Sandmann J, Tsikas D, Boger RH, Bode-Boger SM, et al. Reduced urinary excretion of nitric oxide metabolites and increased plasma levels of asymmetrical dimethylarginine in men with essential hypertension. J Cardiovasc Pharmacol. 1999; 33: 652-658.

19. Fujiwara N, Osanai T, Kamada T, Katoh T, Takahashi K, Okumura K. Study on the relationship between plasma nitrite and nitrate level and salt sensitive in human hypertension. Circulation. 2000; 101: 856-861.

20. Boger RH, Bode-Boger SM, Thiele W, Junker W, Alexander K, Frolich JC. Biochemical evidence for impaired nitric oxide synthesis in patients with peripheral arterial occlusive disease. Circulation. 1997; 95: 2068-2074.

21. Schnabel R, Blankenberg S, Lubos E, Lackner KJ, Rupprecht HJ, EspinolaKlein C, et al. Asymmetric dimethylarginine and the risk of cardiovascular events and death in patients with coronary artery disease: results from the AtheroGene Study Circ Res. 2005; 97: e53-e59.

22. Mittermayer F, Krzyzanowska K, Exner M, Mlekusch W, Amighi J, Sabeti $\mathrm{S}$, et al. Asymmetric dimethylarginine predicts major adverse cardiovascular events in patients with advanced peripheral artery disease. Arterioscler Thromb Vasc Biol. 2006; 26: 2536-2540.

23. Dückelmann C, Mittermayer F, Haider DG, Altenberger J, Eichinger J, Wolzt M. Asymmetric dimethylarginine enhances cardiovascular risk prediction in patients with chronic heart failure. Arterioscler Thromb Vasc Biol. 2007; 27: 2037-2042.

24. Kimoto M, Whitley GS, Tsuji H, Ogawa T. Detection of NG, NG dimethylarginine dimethylaminohydrolase in human tissues using a monoclonal antibody. J Biochem. 1995; 117: 237-238.

25. Zoccali C, Bode-Boger SM, Mallamaci F, Benedetto FA, Tripepi G, Malatino $\mathrm{L}$, et al. Asymmetric dimethylarginine (ADMA): an endogenous inhibitor of 
nitric oxide synthase predicts mortality in end-stage renal disease (ESRD). Lancet. 2001; 358: 2113-2117.

26. Hermenegildo C, Medina P, Peiro M. Plasma concentration of asymmetric dimethylarginine, an endogenous inhibitor of nitric oxide synthase, is elevated in hyperthyroid patients. J Clin Endocrinol Metab. 2002; 87: 5636-5640.

27. Arikan E, Karadag $\mathrm{CH}$, Guldiken S. Asymmetric dimethylarginine levels in thyroid diseases. J Endocrinol Invest. 2007; 30: 186-191.

28. Fazio S, Palmieri EA, Lombardi G. Effects of thyroid hormone on the cardiovascular system. N Engl J Med. 2004; 59: 31-50.

29. Baylis C. Arginine, arginine analogs and nitric oxide production in chronic kidney disease. Nat Clin Pract Nephrol. 2006; 2: 209-220.

30. Teerlink T, Luo Z, Palm F, Wilcox CS. Cellular Adma: Regulation and Action. Pharmacol Res. 2009; 60: 448-460.
31. Schulze F, Maas R, Freese R, Schwedhelm E, Silberhorn E, Böger RH Determination of a reference value for NG, NG-dimethyl-L-arginine in 500 subjects. Eur J Clin Invest. 2005; 35: 622-626.

32. Li XP, Zhou Y, Zhao SP, Cao M, Zhou QC, Li YS. Effect of endogenous estrogen on endothelial function in women with coronary heart disease and its mechanism. Clin Chem Acta. 2004; 339: 183-188.

33. Karkanaki A, Vavilis D, Traianos A, Kalogiannidis I, Panidis D. Hormone therapy and asymmetrical dimethylarginine in postmenopausal women. Hormones (Athens). 2010; 9: 127-135.

34. Teerlink T, Neele SJ, de Jong S, Netelenbos JC, Stehouwer CD. Oestrogen replacement therapy lowers plasma levels of asymmetrical dimethylarginine in healthy postmenopausal women. Clin Sci (Lond). 2003; 105: 67-71.
J Blood Disord - Volume 4 Issue 1 - 2017

ISSN 2379-8009 | www.austinpublishinggroup.com

Al-Nuzaily et al. () All rights are reserved
Citation: Al-Nuzaily MAK, Tash FM, Farid MT, Al-Habori MA, Boshnak $\mathrm{H}$ and Abdelaal H. Asymmetric Dimethylarginine (Adma): A Novel Marker of Endothelial Dysfunction in Hyperthyroidism. J Blood Disord. 2017; 4(1): 1043. 